old in RW and AMPLE, respectively. Concomitant corticosteroids (45\%, 65\%) and methotrexate $(62 \%, 100 \%)$ were common in RW and AMPLE, respectively. All patients in AMPLE were biologic naïve, whereas $83 \%$ of RW patients had prior biologic use. AMPLE administered abatacept subcutaneously (SC), while $37 \%$ of RW patients received abatacept SC. Patients had median SJC and TJC of 6 and 8 in RW and 13 and 22 in AMPLE at abatacept initiation, respectively (Table 2). SJC (TJC) improved a median of $65 \%(60 \%)$ and $68 \%(66 \%)$ at 3 months and $75 \%(67 \%)$ and $76 \%(75 \%)$ at 6 months in RW and AMPLE, respectively (Fig 1). The majority of patients achieved ACR20 at 3 months (79\% and $60 \%$ ) and 6 months (88\% and $66 \%$ ) in RW and AMPLE, respectively, while $58 \%$ and $32 \%$ achieved ACR50 at 3 months and $67 \%$ and $45 \%$ at 6 months, respectively (Fig 2).

Table 2. Changes in Disease Activity.

\begin{tabular}{lcc}
\hline & $\begin{array}{c}\mathbf{R W} \text { cohort } \\
(\mathbf{n}=\mathbf{2 9 1})\end{array}$ & $\begin{array}{c}\text { AMPLE cohort } \\
(\mathbf{n}=\mathbf{3 1 8})\end{array}$ \\
\hline SJC (median) & & \\
Baseline value & 6 & 13 \\
3-month value & 2 & 4 \\
6-month value & 1 & 3 \\
TJC (median) & 8 & 22 \\
Baseline value & 3 & 7 \\
3-month value & 2 & 5 \\
6-month value & 1.08 & 1.6 \\
CRP, mg/dL (mean) & 0.47 & 0.8 \\
Baseline value & 0.30 & 0.8 \\
3-month value & $194(79 \%)$ & $191(60 \%)$ \\
6-month value & $78(88 \%)$ & $209(66 \%)$ \\
ACR20 achieved (n, \%) & & $103(32 \%)$ \\
3-month value & $144(58 \%)$ & $144(45 \%)$ \\
6-month value & $60(67 \%)$ & \\
ACR50 achieved (n, \%) & & \\
3-month value & & \\
6-month value &
\end{tabular}

LEGEND: values soonest after 3 months and value between 6-9 months used for RW cohort; values at days 85 and 197 used for AMPLE cohort.

Conclusion: Despite differences in patient characteristics, improvements in SJC and TJC, as well as high rates of ACR20 and ACR50, were observed in both trial setting and RW settings. These improvements in disease activity were observed at similar magnitudes in both settings, demonstrating that trial efficacy is achievable in RW clinical practice with abatacept treatment.

References:

[1] Kilcher G, Hummel N, Didden EM, et al. Rheumatoid arthritis patients treated in trial and real-world settings: comparison of randomized trials with registries. Rheumatology. 2018;57(2):354-369.

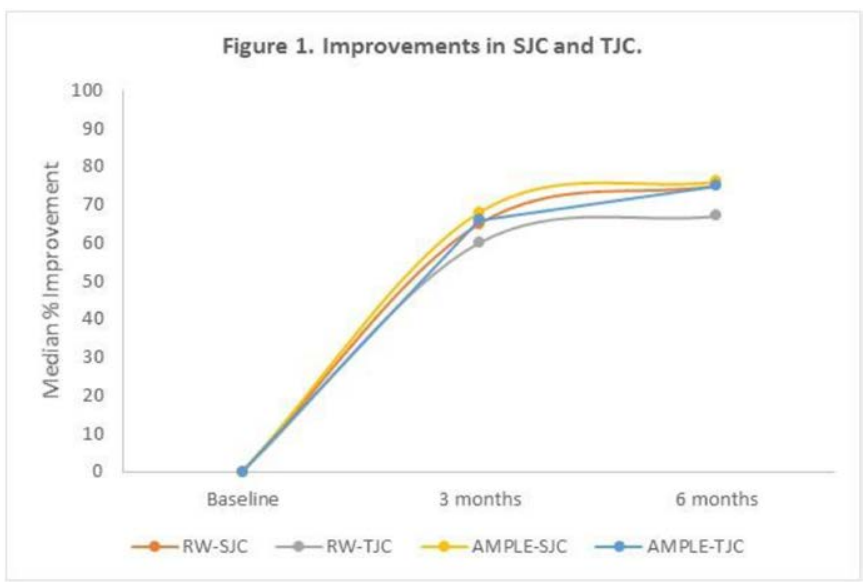

Disclosure of Interests: Andrew Klink Employee of: I am employed by Cardinal Health., Xue Han Employee of: BMS, Francis Lobo Shareholder of: Bristol-Myers Squibb (US), Employee of: Bristol-Myers Squibb (US), Rick Szymialis Shareholder of: BMS, Employee of: BMS, Jenny Lam Shareholder of: A few shares in Gilead in IRA account, Grant/research support from: Currently, a BMS fellowship (not a full-time employee), Bruce Feinberg Employee of: I am employed by Cardinal Health.

DOI: 10.1136/annrheumdis-2020-eular.1453

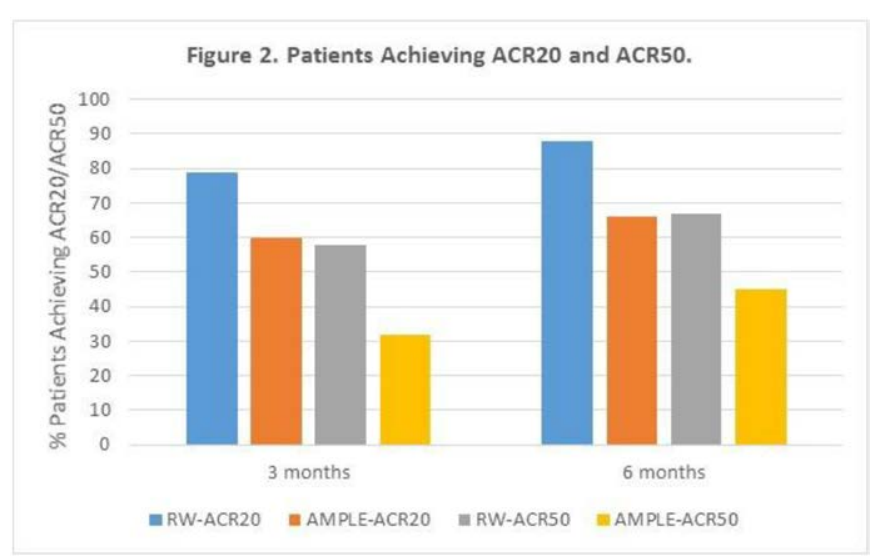

\section{FRI0097 EFFECTS OF BIOLOGICAL DISEASE-MODIFYING ANTI-RHEUMATIC DRUG TREATMENT ON PHYSICAL ACTIVITY, MUSCLE POWER, AGILITY AND INHIBITION OF FALL IN PATIENTS WITH RHEUMATOID ARTHRITIS -THE 2-YEAR RESULTS}

$\underline{\text { Y. Hirano }}^{1}$, A. Morisaka ${ }^{2}$, H. Kosugiyama ${ }^{1}$, S. Inuzuka ${ }^{2}$, T. Kamiya ${ }^{2}$, H. Mori ${ }^{2}$, N. Morishima ${ }^{2}$, T. Ishikawa ${ }^{3} .{ }^{1}$ Toyohashi Municipal Hospital, Rheumatology, Toyohashi, Japan; ${ }^{2}$ Toyohashi Municipal Hospital, Rehabilitation Center, Toyohashi, Japan; ${ }^{3}$ Toyohashi Municipal Hospital, Rehabilitation Medicine, Toyohashi, Japan

Background: Treatment with biological DMARDs (bDMARDs) rapidly improves signs and symptoms in patients with rheumatoid arthritis (RA). The efficacy of these bDMARDs was evaluated using composite measures or biomarkers used in daily clinical practice or clinical studies. Although a rapid improvement in composite measures or biomarkers is important in the treatment of RA, the primary goal of treatment is improvement of long-term health-related quality of life (HR-QOL) [1]. HR-QOL is evaluated based on physical functions (PF) such as muscle power and agility. We reported the 1-year results of our study presented at EULAR 2019 [2]. The present study was conducted to investigate the 2-year results of our study by including more patents than those included in the previous one.

Objectives: This study was aimed at investigating the efficacy of bDMARDs with respect to PF and fall risk in RA patients.

Methods: At our institute, in addition to routine rheumatology evaluation, periodic evaluation of physical function is performed by staff members in our rehabilitation center in RA patients in whom the first bDMARD treatment was initiated in Oct. 2015-Feb. 2018. In total, 41 cases were registered in this study. Evaluation of PF included evaluation of muscle power [grasping power (GP) and knee extension power (KEP)]; agility [time up and go test (TUG) and 10-m walking time (10 $\mathrm{mW})$ ]; and a questionnaire using modified $\mathrm{HAQ}$, portable fall risk index [3], and the 25-question geriatric locomotive function scale (locomo25) [4] at baseline $(\mathrm{BL})$, which implies the time at the initiation of bDMARD treatment, i.e., 1, 3, 6, 12 , and 24 months. Disease activity of RA was evaluated at the same time points. Although 2 years had elapsed from BL in 37 patients, 13 patients dropped out from the evaluation of physical function owing to cessation of bDMARD treatment, rejection of evaluation for physical function, or major joint surgery performed in a patient. The results of 24 patients who completed the evaluation at 24 months were investigated in this study.

Results: Baseline characteristics of the 24 patients were as follows: mean age 60.8 years, RA duration 12.3 years, mean SDAI 19.0, and mean CRP level $2.1 \mathrm{mg} /$ dl. The bDMARDs used in the study were abatacept in 7 patients, adalimumab in 4 patients, tocilizumab in 4 patients, golimumab in 4 patients, etanercept in 3 patients, certolizumab in 1 patient, and an infliximab biosimilar in 1 patients. Data are presented as mean values at $\mathrm{BL}$ and at 1, 3, 6, 12, and 24 months (Fig.1). SDAI and CRP levels were significantly improved at and after 1 month. GP and KEP were significantly improved at and after 3 and 6 months. TUG and $10 \mathrm{~mW}$ results were significantly improved at and after 3 and 6 months. Modified $\mathrm{HAQ}$ results were significantly improved at and after 3 months. Locomo25 scores were significantly improved at and after 1 month. Portable fall risk index values were significantly improved at and after 12 months. 
Fig1. Change of Mean Values and P-value during bDMARDs Treatment in RA Patients

\begin{tabular}{|l|c|c|c|c|c|c|}
\hline & Baseline & $\mathbf{1}$ month & $\mathbf{3}$ months & $\mathbf{6}$ months & $\mathbf{1 2}$ months & $\mathbf{2 4}$ months \\
\hline SDAl & 19.0 (Cont.) & $9.8(<0.01)$ & $6.7(<0.01)$ & $6.3(<0.01)$ & $5.5(<0.01)$ & $4.7(<0.01)$ \\
\hline CRP (mg/dl) & 2.1 (Cont.) & $0.7(<0.01)$ & $0.8(<0.01)$ & $0.7(<0.01)$ & $0.4(<0.01)$ & $0.1(<0.01)$ \\
\hline Grasping Power (kg) & 11.9 (Cont.) & $13.2(0.08)$ & $14.4(<0.01)$ & $15.4(<0.01)$ & $16.6(<0.01)$ & $18.3(<0.01)$ \\
\hline KEP (N/kg) & 3.0 (Cont.) & $3.1(0.11)$ & $3.3(0.08)$ & $3.5(<0.01)$ & $3.7(<0.01)$ & $3.9(<0.01)$ \\
\hline TUG (second) & 9.1 (Cont.) & $8.2(0.055)$ & $8.2(<0.05)$ & $7.4(<0.01)$ & $7.6(<0.05)$ & $7.5(<0.01)$ \\
\hline $10 \mathrm{~mW}$ (second) & 8.0 (Cont.) & $7.5(0.0503)$ & $7.4(0.26)$ & $6.8(<0.01)$ & $6.8<0.01)$ & $6.9(<0.01)$ \\
\hline mHAQ & 0.48 (Cont.) & $0.40(0.12)$ & $0.24(<0.01)$ & $0.26(<0.01)$ & $0.20(<0.01)$ & $0.22(<0.05)$ \\
\hline Locomo25 & 29.1 (Cont.) & $21.1(0.02)$ & $18.4(<0.01)$ & $18.9(<0.01)$ & $16.0(<0.01)$ & $15.0(<0.01)$ \\
\hline Fall risk index & 8.5 (Cont.) & $8.4(0.61)$ & $7.8(0.13)$ & $8.0(0.25)$ & $7.1(<0.01)$ & $7.2(<0.05)$ \\
\hline
\end{tabular}

Data is expressed as mean (p-value). P-value was caluculated using Wilcoxon signed-rank test between baseline and each month.

SDAl: simplified disease activity index, KEP: knee extention power, TUG: timed up and go test, $10 \mathrm{~mW}: 10 \mathrm{~m}$ walking time, $\mathrm{mHAQ}$ : modified health assessment questionnaire

Conclusion: Although there was a rapid improvement in the signs and symptoms of RA after the initiation of bDMARD treatment, improvement in PF was slightly delayed. Significant improvement of muscle power and agility was achieved after 3-6 months onward. Inhibition of fall risk was achieved at and after 12 months after the initiation of bDMARD treatment. These results suggest that physiotherapy plays a vital role in RA patients who undergo treatment with bDMARDs to gain more rapid improvement of PF.

References:

[1] Smolen JS et al. Ann Rheum Dis, 2016.

[2] Hirano Y et al. Ann Rheum Dis, suppl. 2, 2019.

[3] Toba K et al. Jpn J Geriat, 2005.

[4] Seichi A at al. J Orthop Sci, 2012.

Disclosure of Interests: Yuji Hirano Speakers bureau: Tanabe-Mitsubishi, Pfizer, Eisai, Abbie, Chugai, Bristol-Meyers, Jansen, Astellas, UCB, Eli-Lilly, Asahikasei, Daiichi-Sankyo, Amgen, Ayako Morisaka: None declared, Hironobu Kosugiyama: None declared, Shiori Inuzuka: None declared, Takeshi Kamiya: None declared, Hiroyuki Mori: None declared, Naohito Morishima: None declared, Tomoji Ishikawa: None declared

DOI: 10.1136/annrheumdis-2020-eular.2306

\section{FRI0098 ASSOCIATION BETWEEN THE SEROLOGIC STATUS OF ISOTYPE-SPECIFIC AUTOANTIBODIES AND THERAPEUTIC EFFICACY IN RHEUMATOID ARTHRITIS PATIENTS TREATED WITH ABATACEPT: A PROSPECTIVE ULTRASOUND COHORT STUDY IN JAPAN}

S. Y. Kawashiri ${ }^{1,2}$, Y. Endo ${ }^{1,2}$, A. Nishino ${ }^{2}$, T. Shimizu ${ }^{1,2}$, Y. Ueki $^{2}$, N. Eiraku ${ }^{2}$, A. Okada ${ }^{2}$, N. Matsuoka ${ }^{2}$, T. Yoshitama ${ }^{2}$, H. Nakamura ${ }^{1,2}$, M. Tamai $^{1}$, T. Origuchi ${ }^{1,2}$, R. Toes $^{3}$, T. Huizinga ${ }^{3}$, A. Kawakami ${ }^{1}{ }^{1,} .{ }^{1}$ Nagasaki University Graduate School of Biomedical Sciences, Department of Immunology and Rheumatology, Nagasaki, Japan; ${ }^{2}$ Kyushu Multicenter Rheumatoid Arthritis Ultrasound Prospective Observational Cohort Study Group, Nagasaki, Japan ${ }^{3}$ Leiden University Medical Center, Department of Rheumatology, Leiden, Netherlands

Background: The presence of anti-cyclic citrullinated protein antibodies (ACPA) and anti-carbamylated protein (anti-CarP) antibody is specific for rheumatoid arthritis (RA). Recently, it was reported that the serological status of ACPA is associated with the therapeutic response of the T-cell co-stimulation blocker abatacept $(1,2)$. However, it is currently unclear whether the serological status of each isotype levels of these autoantibodies before treatment introduction or the changes during treatment are associated with the therapeutic response of abatacept.

Objectives: To evaluate longitudinal changes in the isotypes of ACPA and antiCarP in RA patients treated with abatacept, and associations between the baseline serological status/ these changes and clinical response/ ultrasonographic response.

Methods: This study is part of an ongoing non-randomized multicenter prospective cohort study of patients with active RA who received biological or targeted DMARD therapy at 13 participating rheumatology centers from the Kyushu region of Japan since June 2013 (3). As of the present report, we enrolled 43 consecutive Japanese patients with active RA who have introduced treatment with abatacept and had finished the first 12-month observation period. We evaluated disease activity by clinical composite measure and ultrasound score at baseline, 3, 6, 9 and 12 months. In ultrasound of bilateral hands from 22 sites, the findings obtained by gray-scale (GS) and power Doppler (PD) assessments were graded on a semi-quantitative scale from 0 to 3 and the sum of GS or PD scores was used as the total GS or PD score. The serum levels of $\mathrm{IgG} / \mathrm{IgM} / \mathrm{IgA}$-type of ACPA and anti-CarP were measured by the ELISA method in Leiden University Medical Center. We evaluated the association between serologic status of autoantibodies and clinical /ultrasonographic therapeutic efficacy.

Results: The median age was 72 years, and the disease duration was 54 months. Methotrexate was concomitant in $22(51 \%)$. Sixteen $(37 \%)$ patients had a history of previous use of biological DMARDs. Nineteen $(44 \%)$ and 23 (54\%) patients achieved SDAI remission and PD remission (total PD score $=0)$ at 12 months, respectively. The serum levels of all isotypes of ACPA/antiCarP significantly decreased at 12 months from baseline. The reduction of IgM-ACPA level significantly correlated with the reduction of SDAI ( $r s=0.33$, $p=0.031)$ and total PD score ( $r s=0.49, p=0.0007)$. Both clinical and ultrasonographic therapeutic responses were better in patients with the detectable IgMACPA at baseline than in patients without that (Figure): the reduction of SDAI $(p=0.0078)$ and that of total PD score $(p=0.0079)$ were significantly larger in the former than in the latter. All isotype of anti-CarP did not associate with therapeutic response.

Conclusion: Treatment of abatacept induced to the reduction of the autoantibody levels. The IgM-ACPA level at baseline and the change in IgM-ACPA associated with both clinical and ultrasonographic therapeutic response in patients treated with abatacept. IgM-ACPA, compared with usual IgG-ACPA, better reflects the treatment response of abatcept in patients with $\mathrm{RA}$

References:

[1] Ann Rheum Dis. 2016;75:709, 2) RMD Open. 2018;4:e000564, 3)Arthritis Care Res (Hoboken). 2018;70:1719.

Figure 1. Clinical and ultrasonographic response in patients with the detectable IgM-ACPA at baseline $(A)$ than in patients without that $(B)$

(A)

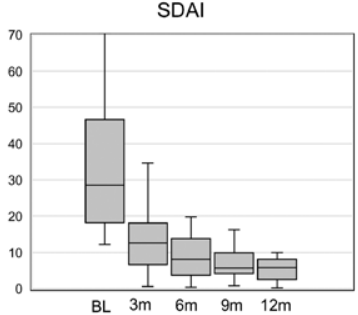

SDAI

B)
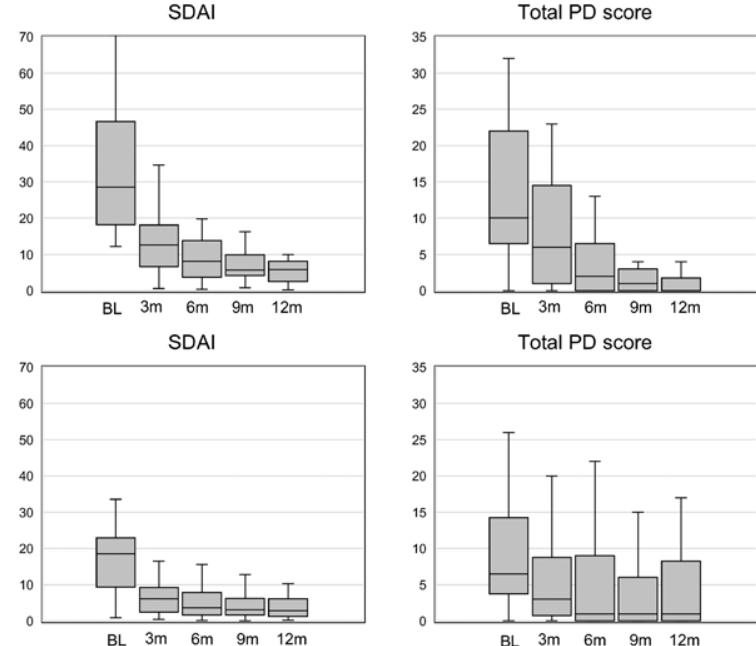

Total PD score

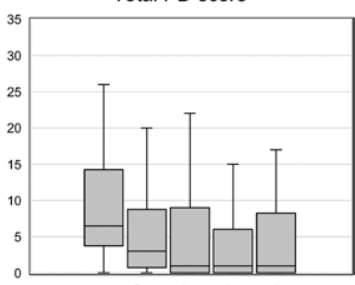

BL $3 \mathrm{~m} \quad 6 \mathrm{~m} \quad 9 \mathrm{~m} \quad 12 \mathrm{~m}$

Acknowledgments: We have acknowledged for all the members of Kyushu multicenter rheumatoid arthritis ultrasound prospective observational cohort study group.

Disclosure of Interests: Shin-ya Kawashiri Grant/research support from: This work was supported by Bristol-Myers Squibb and Ono Pharmaceutical. co., Yushiro Endo: None declared, Ayako Nishino: None declared, Toshimasa Shimizu: None declared, Yukitaka Ueki: None declared, Nobutaka Eiraku: None declared, Akitomo Okada: None declared, Naoki Matsuoka: None declared, Tamam Yoshitama: None declared, Hideki Nakamura: None declared, Mami Tamai: None declared, Tomoki Origuchi: None declared, Rene Toes: None declared, Thomas Huizinga Grant/research support from: Ablynx, Bristol-Myers Squibb, Roche, Sanofi, Consultant of: Ablynx, Bristol-Myers Squibb, Roche, Sanofi, Atsush Kawakami: None declared

DOI: 10.1136/annrheumdis-2020-eular.2269

\begin{tabular}{l|l}
\hline FRI0099 & THE IMPACT OF BIOLOGICAL DISEASE-MODIFYING \\
& ANTI-RHEUMATIC DRUGS ON THE COURSE OF \\
& RHEUMATOID ARTHRITIS-ASSOCIATED LUNG \\
& DISEASE
\end{tabular}

A. Köken Avșar ${ }^{1}$, G. Can ${ }^{1}$, M. Birlik ${ }^{1}$, I. Sari ${ }^{1}$, F. Onen ${ }^{1} .{ }^{1}$ Dokuz Eylul University Medical School, Rheumatology Department, Izmir, Turkey 